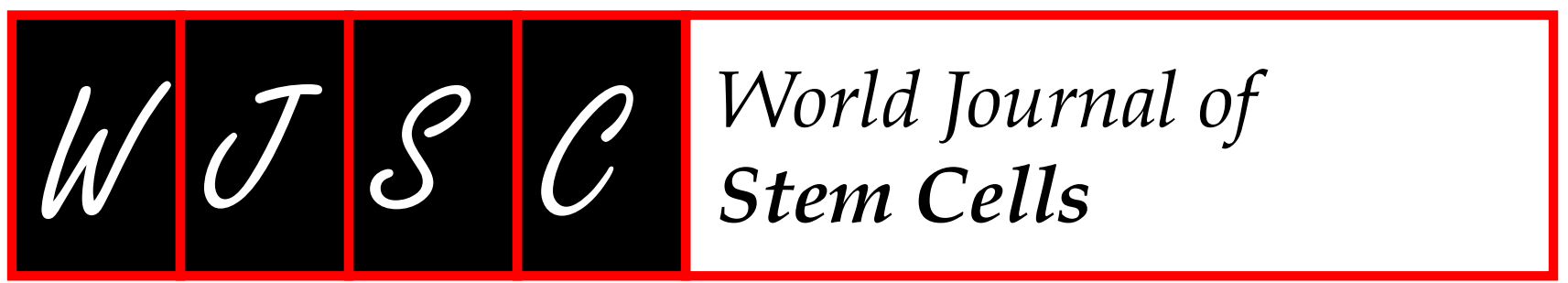

\title{
Regenerative potential of mouse embryonic stem cell-derived PDGFRa+ cardiac lineage committed cells in infarcted myocardium
}

\author{
Seon Pyo Hong, Sukhyun Song, Seungjoo Lee, Hyeonju Jo, Hyoung Kyu Kim, Jin Han, Jae-Hyeong Park, \\ Sung Woo Cho
}

ORCID number: Seon Pyo Hong (0000-0002-9923-8099); Sukhyun Song (0000-0002-8299-9270); Seungjoo Lee

(0000-0003-0641-3917); Hyeonju Jo (0000-0003-1091-4116); Hyoung Kyu Kim (0000-0002-1791-7865); Jin Han (0000-0003-1859-3425); Jae-Hyeong Park (0000-0001-7035-286X); Sung Woo Cho (0000-0003-3983-817X).

Author contributions: Hong SP and Song $S$ contributed equally to this work; Hong SP and Song S performed the majority of experiments; Hong SP, Song S and Cho SW conceptualized the original idea, designed the experiments and analyzed the data; Hong SP and Lee S made myocardial infarction murine models; Park JH performed the transthoracic echocardiography and analyzed the data; Jo H, Kim $\mathrm{HK}$ and Han J coordinated and supervised the research; Hong SP, Song $S$ and Cho SW wrote the paper.

\section{Supported by Basic Science} Research Program through the National Research Foundation of Korea (NRF) funded by the Ministry of Education, No. 2017R1D1A3B03034465; the 2017 Inje University research grant, and Priority Research Centers Program through the NRF funded by the Ministry of Education, Science, and Technology, No. 2010-0020224.

Institutional animal care and use committee statement: Approved by the Animal Care Committee of KAIST (KA2013-40).
Seon Pyo Hong, Sukhyun Song, Center for Vascular Research, Institute of Basic Science (IBS), Daejeon 34141, South Korea

Seungjoo Lee, Department of Neurosurgery, Asan Medical Center, University of Ulsan College of Medicine, Seoul 05505, South Korea

Hyeonju Jo, Hyoung Kyu Kim, Jin Han, Cardiovascular and Metabolic Disease Center, Department of Physiology, Department of Health Sciences and Technology, BK21 plus Project Team, Inje University College of Medicine, Busan 47392, South Korea

Jae-Hyeong Park, Department of Cardiology in Internal Medicine, School of Medicine, Chungnam National University Hospital, Chungnam National University, Daejeon 35015, South Korea

Sung Woo Cho, Division of Cardiology, Department of Internal Medicine, Inje University College of Medicine, Seoul Paik Hospital, Seoul 04551, South Korea

Sung Woo Cho, Cardiovascular and Metabolic Disease Center, Inje University College of Medicine, Busan 47392, South Korea

Corresponding author: Sung Woo Cho, MD, PhD, Assistant Professor, Division of Cardiology, Department of Internal Medicine, Inje University College of Medicine, Seoul Paik Hospital, 9 Mareunnae-ro, Jung-gu, Seoul 04551, South Korea. drswcho@hanmail.net

Telephone: $+82-2-22700010$

Fax: $+82-2-22700312$

\section{Abstract}

\section{BACKGROUND}

Pluripotent stem cell-derived cardiomyocytes (CMs) have become one of the most attractive cellular resources for cell-based therapy to rescue damaged cardiac tissue.

\section{AIM}

We investigated the regenerative potential of mouse embryonic stem cell (ESC)derived platelet-derived growth factor receptor- $\alpha$ (DGFRa) $)^{+}$cardiac lineagecommitted cells (CLCs), which have a proliferative capacity but are in a morphologically and functionally immature state compared with differentiated CMs.

\section{METHODS}


Conflict-of-interest statement: No potential conflicts of interest relevant to this article were reported.

ARRIVE guidelines statement: The authors have read the ARRIVE guidelines, and the manuscript was prepared and revised according to the ARRIVE guidelines.

Open-Access: This article is an open-access article which was selected by an in-house editor and fully peer-reviewed by external reviewers. It is distributed in accordance with the Creative Commons Attribution Non Commercial (CC BY-NC 4.0) license, which permits others to distribute, remix, adapt, build upon this work non-commercially, and license their derivative works on different terms, provided the original work is properly cited and the use is non-commercial. See: http://creativecommons.org/licen ses/by-nc/4.0/

Manuscript source: Invited manuscript

Received: October 29, 2018 Peer-review started: October 29 2018

First decision: November 29, 2018

Revised: December 6, 2018

Accepted: January 5, 2019

Article in press: January 6, 2019

Published online: January 26, 2019
We induced mouse ESCs into PDGFRa ${ }^{+} \mathrm{CLC}$ s and $\mathrm{aMHC}^{+} \mathrm{CMs}$ using a combination of the small molecule cyclosporin A, the rho-associated coiled-coil kinase inhibitor Y27632, the antioxidant Trolox, and the ALK5 inhibitor EW7197. We implanted PDGFRa ${ }^{+}$CLCs and differentiated $\mathrm{aMHC}^{+} \mathrm{CM}$ into a myocardial infarction (MI) murine model and performed functional analysis using transthoracic echocardiography (TTE) and histologic analysis.

\section{RESULTS}

Compared with the untreated MI hearts, the anterior and septal regional wall motion and systolic functional parameters were notably and similarly improved in the MI hearts implanted with PDGFRa ${ }^{+}$CLCs and aMHC ${ }^{+} \mathrm{CMs}$ based on TTE. In histologic analysis, the untreated MI hearts contained a thinner ventricular wall than did the controls, while the ventricular walls of MI hearts implanted with PDGFRa ${ }^{+} \mathrm{CLC}$ s and $\mathrm{aMHC}^{+} \mathrm{CMs}$ were similarly thicker compared with that of the untreated MI hearts. Furthermore, implanted PDGFRa ${ }^{+}$CLCs aligned and integrated with host $\mathrm{CMs}$ and were mostly differentiated into a-actinin ${ }^{+} \mathrm{CMs}$, and they did not convert into $\mathrm{CD} 31^{+}$endothelial cells or aSMA+ mural cells.

\section{CONCLUSION}

PDGFRa ${ }^{+}$CLCs from mouse ESCs exhibiting proliferative capacity showed a regenerative effect in infarcted myocardium. Therefore, mouse ESC-derived PDGFRa $^{+}$CLCs may represent a potential cellular resource for cardiac regeneration.

Key words: Pluripotent stem cell; Embryonic stem cell; Cardiomyocyte; Myocardial infarction; Regeneration

CThe Author(s) 2019. Published by Baishideng Publishing Group Inc. All rights reserved.

Core tip: We demonstrated that mouse embryonic stem cell-derived platelet-derived growth factor receptor- $\alpha^{+}$cardiac lineage-committed cells have proliferative capacity but are in a morphologically and functionally immature state compared with differentiated cardiomyocytes; these cells exerted a regenerative effect on infarcted myocardium.

Citation: Hong SP, Song S, Lee S, Jo H, Kim HK, Han J, Park JH, Cho SW. Regenerative potential of mouse embryonic stem cell-derived PDGFR $\alpha^{+}$cardiac lineage committed cells in infarcted myocardium. World J Stem Cells 2019; 11(1): 44-54

URL: https://www.wjgnet.com/1948-0210/full/v11/i1/44.htm

DOI: https://dx.doi.org/10.4252/wjsc.v11.i1.44

\section{INTRODUCTION}

Myocardial infarction (MI) and heart failure are the most common causes of death in patients with cardiovascular disease ${ }^{[1]}$. Despite remarkable advances in therapeutic strategies for heart failure, such as novel drugs, ventricular assist device implantation, and heart transplantation, the burden of the disease remains high. Cardiac regeneration using stem cell therapy is an attractive therapeutic strategy to rescue damaged cardiac tissue ${ }^{[2]}$. Among stem cell populations, pluripotent stem cells (PSCs) such as embryonic stem cells (ESCs) and induced pluripotent stem cells (iPSCs), exhibit a higher efficacy in cardiomyocyte induction and expansion rate compared with adult stem cells ${ }^{[2]}$. Indeed, previous large numbers of reports demonstrated functional improvement of damaged myocardium in murine, rodent, and porcine MI models that received PSC-derived cardiomyocytes $(\mathrm{CMs})^{[2-4]}$.

However, the proliferative capacity of PSC-derived CMs is decreased after beating and terminal differentiation ${ }^{[5]}$. Furthermore, there is no definite surface marker of differentiated PSC-derived CMs to facilitate purification ${ }^{[6]}$. Recently, several studies have been conducted to identify a novel marker for cardiac progenitor or cardiac lineage-committed cells (CLCs), which are intermediate-stage cells between mesodermal cells and differentiated CMs with proliferative capacity ${ }^{[7-10]}$. Our group previously established a novel class of cells from PSCs-platelet-derived growth factor receptor- $\alpha$ (PDGFRa) $)^{+}$CLCs-induced using a combination of four specific modulators: 
the mitochondrial permeability transition pore inhibitor cyclosporin A (CsA), the ROCK inhibitor Y27632, the antioxidant Trolox, and the activin A receptor type II-like kinase (ALK5) inhibitor EW7197 (collectively referred to here as CsAYTE) ${ }^{[11]}$. This novel population of actively proliferating cells is cardiac lineage-committed but in a morphologically and functionally immature state compared with differentiated $\mathrm{CMs}^{[11]}$. In the present study, we investigated the regenerative potential of mouse ESC-derived PDGFRa ${ }^{+}$CLCs in a murine MI model and compared their efficacy with differentiated CMs.

\section{MATERIALS AND METHODS}

\section{Mouse ESCs and OP9 cell culture}

EMG7 mouse ESCs, which have an aMHC promoter-driven enhanced GFP gene, E14Tg2a ESCs, and OP9 cells were generated as described previously ${ }^{[12-14]}$ and transferred to KAIST.

\section{Generation of EMG7 mouse ESCs expressing tdTomato fluorescence}

Lentiviruses were generated by transfecting FUtdTW (Addgene plasmid 22478) ${ }^{[15]}$ with pMD2.G (Addgene plasmid 12259), pMDLg/pRRE (Addgene plasmid 12251) and pRSV-Rev (Addgene plasmid 12253) ${ }^{[16]}$ in 293 T cells using jetPEI (Polypustransfection). Supernatants were collected $48 \mathrm{~h}$ after transfection, filtered through a $0.45 \mu \mathrm{m}$ filter, and concentrated by Lenti-X concentrator (Clontech). Viral particles were resuspended in ESC medium with $4 \mathrm{mg} / \mathrm{mL}$ polybrene. EMG7 mouse ESCs were incubated in this medium for $24 \mathrm{~h}$. Selection of ESCs was performed by FACS sorting.

\section{Induction of mouse ESC-derived mesodermal precursor cells and CLCs}

For the induction of Flk1 $1^{+}$mesodermal precursor cells (MPCs), ESCs were cultured without leukemia inhibitory factor (LIF, Millipore) and plated on a $0.1 \%$ gelatincoated dish at a cell density between $1 \times 10^{3}$ and $1.5 \times 10^{3}$ cells $\mathrm{cm}^{2}$ in the differentiation medium, which is aMEM (Invitrogen) containing $10 \%$ fetal bovine serum (FBS, Welgene), $0.1 \mathrm{mmol} / \mathrm{L}$ of 2-mercaptoethanol (Invitrogen), $2 \mathrm{mmol} / \mathrm{L}$ of L-glutamine (Invitrogen) and $50 \mathrm{U} / \mathrm{mL}$ of penicillin-streptomycin (Invitrogen). Medium was changed every other day for $4.5 \mathrm{~d}$. At day 4.5, differentiated ESCs were harvested with $0.25 \%$ trypsin-EDTA (Invitrogen), and antigen retrieval was performed in the differentiation medium for $30 \mathrm{~min}$ in an incubator. Then, cells were washed using $2 \%$ FBS in phosphate buffered saline (PBS) and incubated with biotinconjugated anti-mouse Flk1 antibody (clone AVAS12a1, eBioscience) and antistreptavidin MicroBeads (Miltenyi Biotec). Flk1 $1^{+}$MPCs were sorted by AutoMACS Pro Separator (Miltenyi Biotec). For induction of CLCs, sorted Flk1 $1^{+}$MPCs were plated onto the mitomycin C (AG Scientific)-treated confluent OP9 cells at a density of $5-10 \times 10^{3}$ cells $\mathrm{cm}^{2}$ in the medium containing $3 \mu \mathrm{g} / \mathrm{mL}$ of CsA, $10 \mu \mathrm{mol} / \mathrm{L}$ of Y27632, $400 \mu \mathrm{mol} / \mathrm{L}$ of Trolox, and $1 \mu \mathrm{g} / \mathrm{mL}$ of EW7197 (CsAYTE) ${ }^{[11,17]}$. The medium was refreshed every other day. Live images of differentiation process of CLCs and CMs were obtained using Axiovert 200M microscope (Carl Zeiss) equipped with AxioCam MRm (Carl Zeiss). Phase contrast images including beating CMs were obtained using an Infinity $X$ digital camera and DpxView LE software (DeltaPix).

\section{Flow cytometry analysis and cell sorting}

The cells were harvested with $0.25 \%$ trypsin-EDTA or dissociation buffer (Invitrogen). To analyze live cells, antigen retrieval was performed in the differentiation medium for $30 \mathrm{~min}$ in an incubator and the cells were incubated for $20 \mathrm{~min}$ with the following antibodies: Allophycocyanin-conjugated anti-mouse PDGFRa (eBioscience, 17-1401, clone APA5, 1:100) and phycoerythrin/Cy7-conjugated anti-mouse Flk1 (BioLegend, 136414, clone AVAS12a1, 1:50). In live cell analysis and sorting, dead cells were excluded using 4,6-diamidino-2-phenylindole (DAPI, Sigma, D8417, 1:1000), and OP9 cells were excluded from Flk1+ MPC by gating in flow cytometry. The differentiated CMs were sorted using aMHC-GFP. Analyses and sorting were performed by FACS Aria II (Beckton Dickinson). Data were analyzed using FlowJo Version 7.5.4 software (TreeStar).

\section{Animals}

Twenty eight male 9-wk-old BALB/c nude mice were kept in the specific pathogen free before the experiment under a 12:12 h light/dark cycle with lights on at 8:00 AM. They were deprived of food for $18 \mathrm{~h}$ but permitted water ad libitum before surgery. Animal care and experimental procedures were performed to conform the NIH guidelines (Guide for the care and use of laboratory animals) and approved by the 
Animal Care Committee of KAIST (KA2013-40).

\section{Preparation of acute MI model in mouse and cell transplantation}

All mice were anesthetized through an intraperitoneal injection of a combination of anesthetics ( $80 \mathrm{mg} / \mathrm{kg}$ ketamine, $12 \mathrm{mg} / \mathrm{kg}$ xylazine) before any procedures. After intubation, the mice were ventilated with room air (SomnoSuiteTM, Kent scientific). MI was induced by exposing the heart by left thoracotomy and permanently ligating the proximal portion of left anterior descending coronary artery with an 8-0 prolene thread under respiratory support. After ligating the proximal portion of left anterior descending coronary artery, infarction of the anterior wall of left ventricle was confirmed in each mouse by the presence of a pale anterior wall and myocardial hypokinesis. Immediately after ligation of coronary artery and the confirmation of infarction, $100 \mu \mathrm{L}$ PBS containing $1 \times 10^{6} \mathrm{PDGFRa}^{+} \mathrm{CLCs}$ or $\mathrm{aMHC}^{+} \mathrm{CMs}$ were intramyocardially injected with a 31-gauge $(0.25 \mathrm{~mm})$ insulin syringe into the 3 different sites along the borderline of the infarcted area.

\section{Transthoracic echocardiographic analysis}

Transthoracic echocardiography (TTE) studies were performed (VIVID 7 dimension system, General Electric-Vingmed Ultrasound) $15 \mathrm{~d}$ after MI surgery and cell implantation. Images were obtained using an i13L transducer $(5.3-14.0 \mathrm{MHz}, \mathrm{GE}$ Healthcare) with high temporal and spatial resolution. Two-dimensionally targeted M-mode parameters were measured at a level of papillary muscle in parasternal short axis view during 6 consecutive cardiac beats. All measurements were performed in a blind fashion according to the guidelines of American Society for Echocardiography.

\section{Histologic and morphometric analyses}

Before sacrifice, mice were anesthetized with a mixture of ketamine $(80 \mathrm{mg} / \mathrm{kg})$ and xylazine $(10 \mathrm{mg} / \mathrm{kg})$. For hematoxylin and eosin $(\mathrm{H}$ and $\mathrm{E})$ staining, samples were fixed overnight with $4 \%$ paraformaldehyde and embedded in paraffin after tissue processing. For immunofluorescence staining, samples were fixed in $4 \%$ paraformaldehyde, dehydrated in $20 \%$ sucrose solution overnight, and embedded in tissue freezing medium (Leica). Samples were blocked with $5 \%$ goat (or donkey) serum in $0.01 \%$ Trition X-100 in PBS and then incubated overnight at $4{ }^{\circ} \mathrm{C}$ with the following primary antibodies: Mouse anti-a-actinin monoclonal antibody (Sigma Aldrich, A7811, clone EA-53, 1:100) or rabbit anti-a-actinin polyclonal antibody (Abcam, ab68167, clone EP2529Y, 1:100), rabbit anti-Ki-67 polyclonal antibody (Abcam, ab15580, 1:200), mouse anti-a-SMA monoclonal antibody (Sigma Aldrich, A2547, clone 1A4, 1:500), hamster anti-CD31 monoclonal antibody (Millipore, MAB1398Z, clone 2H8, 1:400), and rabbit anti-GFP polyclonal antibody (Millipore, AB3080, 1:200). After several washes, the samples were incubated for $2 \mathrm{~h}$ at RT with the following secondary antibodies: Cy5-conjugated anti-mouse IgG (Jackson ImmunoResearch, 715-175-150, 1:1000) and Cy3-, Cy5-, FITC-conjugated anti-rabbit IgG antibodies (Jackson ImmunoResearch, 711-165-152, 711-175-152, 711-095-152, 1:1000). Then the samples were mounted with fluorescent mounting medium (DAKO) and immunofluorescent images were acquired using a Zeiss LSM780 confocal microscope (Carl Zeiss). To calculate capillary density, number of $\mathrm{CD} 31^{+}$endothelial cells was counted per random $0.5 \mathrm{~mm}^{2}$ area in the infarcted myocardium at $15 \mathrm{~d}$ after cell implantation. To analyze the regenerative effects of host myocardium, number of $\mathrm{Ki}-67^{+} / \mathrm{a}$-actinin ${ }^{+} \mathrm{CMs}$ was counted per 104 nuclei in the peri-infarcted area, ranged within $200 \mu \mathrm{m}$ from infarcted region, at 3 and $15 \mathrm{~d}$ after cell implantation. Images were analyzed using ImageJ software (http:/ / imagej.nih.gov/ij/, 1.47V, NIH, United States).

\section{Statistical analysis}

Values are presented as mean \pm SD. For continuous data, statistical significance was determined with the Mann-Whitney $U$ test between 2 groups and the Kruskal-Wallis test followed by Tukey's honest significant difference test with ranks or multiplegroup comparison. Statistical analysis was performed with SAS 9.4 (SAS Institute Inc). Statistical significance was set at $P<0.05$ or 0.01 .

\section{RESULTS}

Implantation of PDGFRa ${ }^{+}$CLCs and $a M H C^{+}$CMs equally improves contractile function and structure in infarcted heart

To investigate the regenerative potential of PDGFRa ${ }^{+} \mathrm{CLCs}$ and $\mathrm{aMHC}^{+} \mathrm{CMs}$, cells were sorted, and approximately $1 \times 10^{6}$ of each were implanted into the left 
ventricular myocardium after inducing acute MI. The results of the recipient groups were compared with those of MI hearts without implantation. Analyses were performed at $2 \mathrm{wk}$ after implantation of cells (Figure 1A). To trace the implanted cells in the infarcted heart, we induced PDGFRa ${ }^{+}$CLCs from ESCs expressing tdTomato fluorescence (Figure 1B). As shown in Figure 1C, the implanted cells were mainly distributed along several myocardial cavities $1 \mathrm{~h}$ after implantation.

First, to evaluate the functional recovery of infarcted hearts after cell implantation, we performed TTE $14 \mathrm{~d}$ after implantation. Compared with that in untreated MI hearts, the anterior and septal regional wall motion was notably and similarly improved (see arrowheads in Figure 2A) in the MI hearts implanted with PDGFRa ${ }^{+}$ CLCs (hereafter designated as MI+PDGFRa ${ }^{+} \mathrm{CLCs}$ ) and $\mathrm{aMHC}^{+} \mathrm{CMs}$ (designated as $\mathrm{MI}+\mathrm{aMHC}^{+} \mathrm{CMs}$ ). Moreover, the left ventricular internal dimension during systole of both MI+PDGFRa ${ }^{+} \mathrm{CLCs}$ and $\mathrm{MI}+\alpha \mathrm{MHC}^{+} \mathrm{CMs}$ was approximately $12 \%-23 \%$ less compared with that of untreated MI hearts (Figure 2B). Both MI+PDGFRa ${ }^{+}$CLCs and $\mathrm{MI}+\mathrm{aMHC}^{+} \mathrm{CMs}$ also showed significant and similar improvements in systolic functional parameters, which included an ejection fraction increased by $20.0 / 15.6 \%$ and fractional shortening increased by $9.5 / 7.2 \%$, respectively, compared with those of untreated MI hearts (Figure 2C). All TTE parameters are summarized in Table 1. These findings indicate that the implantation of PDGFRa ${ }^{+} \mathrm{CLCs}$ and $\mathrm{aMHC}^{+} \mathrm{CMs}$ had similar beneficial effects in the functional recovery of acutely infarcted hearts. Next, to confirm whether the implanted cells were properly engrafted to the infarcted myocardium, we performed histologic analyses at $15 \mathrm{~d}$ after implantation. Overall, the gross sizes of MI+PDGFRa ${ }^{+} \mathrm{CLCs}$ and $\mathrm{MI}+\mathrm{aMHC}^{+} \mathrm{CMs}$ were smaller than that of untreated MI hearts (Figure 2D). Hematoxylin and eosin staining showed that untreated MI hearts had a thinner ventricular wall $(0.19 \mathrm{~mm})$ than did controls, while the ventricular walls of $\mathrm{MI}+\mathrm{PDGFRa}^{+} \mathrm{CLC}$ s and $\mathrm{MI}+\mathrm{aMHC}^{+} \mathrm{CMs}$ were similarly thicker ( $0.47 \mathrm{~mm}$ and $0.39 \mathrm{~mm}$, respectively) compared with that of untreated $\mathrm{MI}$ hearts (Figures 2E and F).

\section{Integration, differentiation, proliferation, and survival of implanted PDGFRa ${ }^{+}$CLCs} in the infarcted heart

Importantly, implanted $\mathrm{PDGFRa}^{+} \mathrm{CLC}$ and $\mathrm{aMHC}^{+} \mathrm{CMs}$ were visible as tdTomato $^{+} /$a-MHC-GFP ${ }^{+}$cells aligned and integrated with host CMs (Figure 3A). Implanted PDGFRa ${ }^{+} \mathrm{CLCs}$ and $\mathrm{aMHC}^{+} \mathrm{CMs}$ were mostly differentiated into aactinin ${ }^{+} \mathrm{CMs}$, and they did not convert into $\mathrm{CD}^{+} 1^{+}$endothelial cells or aSMA ${ }^{+}$mural cells (Figures 3B and C). Moreover, $\mathrm{CD}^{+} 1^{+}$blood vessels in the infracted area increased by 2.1- and 1.8-fold in MI+PDGFRa ${ }^{+} \mathrm{CLCs}$ and $\mathrm{MI}+\mathrm{aMHC}^{+} \mathrm{CMs}$ at day 15 after implantation (Figures $4 \mathrm{~A}$ and $\mathrm{B}$ ), while the numbers of $\mathrm{Ki}-67^{+} \mathrm{CMs}$ also transiently increased equally by 2.4-fold at day 3; no such increases were detected at day 15 in both groups (Figures $4 \mathrm{C}$ and D). Thus, in addition to integration of implanted $\mathrm{MI}+\mathrm{PDGFRa}^{+} \mathrm{CLC}$ and $\mathrm{MI}+\mathrm{aMHC}^{+} \mathrm{CMs}$ into the host myocardium, paracrine effects of $\mathrm{MI}+\mathrm{PDGFRa}^{+} \mathrm{CLC}$ s and $\mathrm{MI}+\mathrm{aMHC}^{+} \mathrm{CMs}$ appeared to be involved in the functional recovery of acutely infarcted hearts. Both types of implanted cells persisted up to $60 \mathrm{~d}$ after implantation (Figure 4E), which was the longest observation period in this study.

\section{DISCUSSION}

In the present study, we demonstrated the regenerative potential of mouse ESCderived PDGFRa ${ }^{+}$CLCs in a murine MI model. Implantation of PDGFRa ${ }^{+}$CLCs and $\mathrm{aMHC}^{+} \mathrm{CMs}$ equally improved the contractile function and structure in the infarcted heart. Notably, implanted PDGFRa ${ }^{+}$CLCs were well integrated with host CMs and mostly differentiated into CMs.

Various transcription factors and cell-surface markers of cardiac progenitors or CLCs have been identified in previous studies ${ }^{[6]}$. Our group developed PDGFRa ${ }^{+}$ CLCs induced by CsAYTE, which significantly enhanced the commitment of mesodermal cells to CLCs; in addition, the PDGFRa ${ }^{+}$CLCs can spontaneously further differentiate into CMs without additional manipulation or stimulation under in vitro conditions $^{[11]}$. However, there are few studies regarding the engraftment and regenerative potential of cardiac progenitors or CLCs compared with differentiated CMs after implantation under in vivo pathologic conditions ${ }^{[18,19]}$. Takeda et al ${ }^{[7]}$ recently found that human iPSC-derived CM-fated progenitors from a subpopulation of kinase insert domain receptor $(\mathrm{KDR})^{+}$and $\mathrm{PDGFRa}^{+}$cells express CD82 $2^{[7]}$. Consistent with our findings, purified $\mathrm{CD} 82^{+}$cells gave rise to $\mathrm{CMs}$ under both in vitro and in vivo conditions $^{[7]}$. Interestingly, CD82 ${ }^{+}$cells showed considerably greater engraftment than differentiated vascular cell adhesion molecule 1 (VCAM1) ${ }^{+}$CMs after transplantation 
A

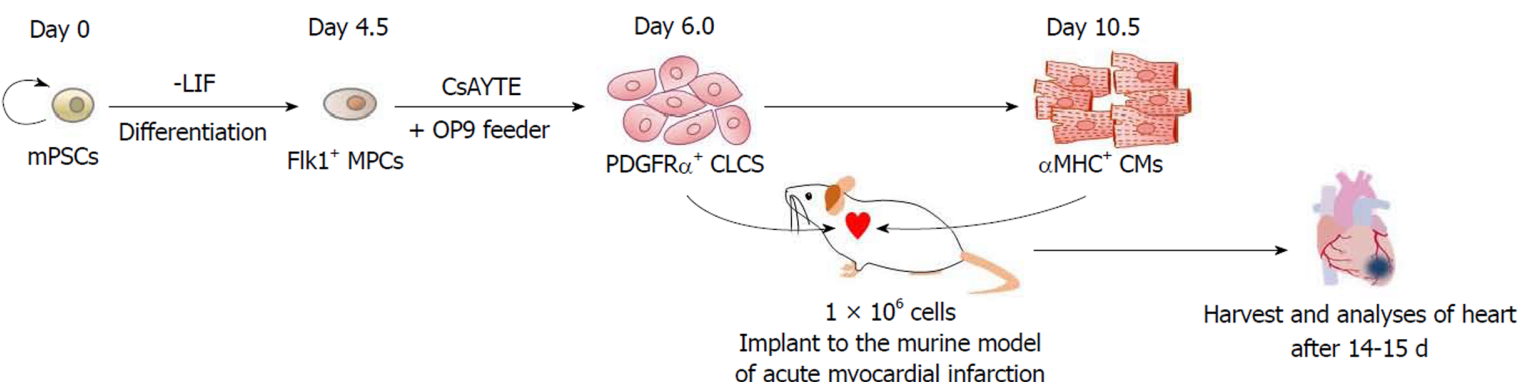

B

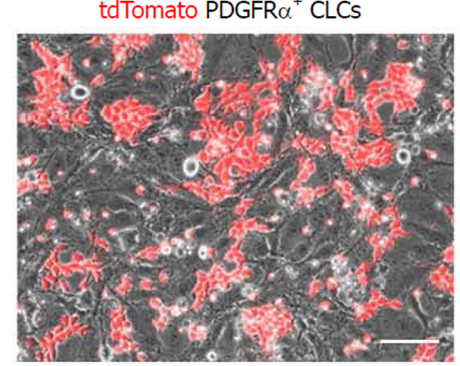

C

MI+PDGFRo ${ }^{+}$CLC 1 h after implantation

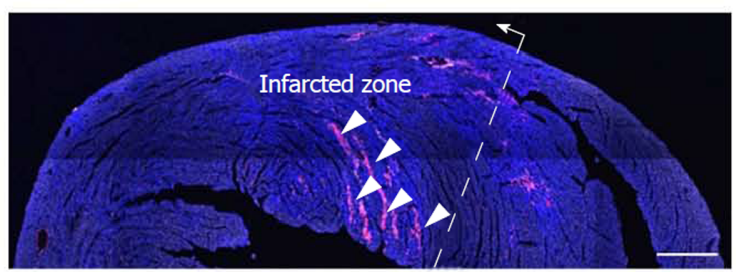

tdTomato $\alpha$-actinin DAPI

Figure 1 Implantations of platelet-derived growth factor receptor- $\alpha^{+}$cardiac lineage-committed cells and $\mathrm{aMHC}^{+}$cardiomyocytes in the acute myocardial infarction murine model. A: Experimental scheme of implanting either platelet-derived growth factor receptor-a (PDGFRa) ${ }^{+}$cardiac lineage-committed cells (CLCs) or $\mathrm{aMHC}^{+}$cardiomyocytes $(\mathrm{CMs})$ into acute myocardial infarction (MI) murine model. Analyses were performed at 2 wk after implantation of approximately $1 \times 10^{6}$ cells of PDGFRa ${ }^{+} \mathrm{CLCs}$ or $\mathrm{aMHC}^{+} \mathrm{CMs}$ into the left ventricular myocardium of acute Ml murine model; $\mathrm{B}$ : Live cell image showing tdTomato ${ }^{+}$cells during induction of PDGFRa ${ }^{+}$CLCs from embryonic stem cells. Scale bars, $100 \mu \mathrm{m}$; C: Representative confocal image showing implanted tdTomato ${ }^{+}$PDGFRa $^{+} \mathrm{CLCs}_{\text {in }}$ the myocardial spaces (arrowheads) of the infarcted zone (dotted line and arrow), which was formed by ligation of coronary artery $1 \mathrm{~h}$ prior to the implantation. Scale bar, $500 \mu \mathrm{m}$. CLCs: Cardiac lineage-committed cells; CMs: Cardiomyocytes; PSCs: Pluripotent stem cells; ESCs: Embryonic stem cells; LIF: Leukemia inhibitory factor.

to the subrenal space ${ }^{[7]}$. These data indicated that the proliferative capacity of CLCs is higher than that of differentiated CMs under in vivo conditions. Furthermore, CD82+ cells primarily differentiated into CMs within infarcted hearts at approximately $95 \%$ efficiency; nevertheless, there were no data related to functional and structural recovery in the infarcted hearts ${ }^{[7]}$. The LIM-homeodomain transcription factor ISL1 is the most well-known marker of cardiac progenitors, and recent studies demonstrated that ISL1 ${ }^{+}$cardiac progenitors also exhibit regenerative potential in the infarcted heart ${ }^{[20,21]}$. Another developed strategy, direct reprogramming, was used to generate proliferative induced cardiac progenitors from fibroblasts with cardiac-specific transcription factors (Mesp1, Tbx5, Gata4, Nkx2.5, and Baf60c), and these reprogrammed cells were revealed to have regenerative potential in $\mathrm{MI}^{[22,23]}$. Collectively, the previous and current data provide compelling evidence that cardiac progenitors or CLCs are potential cellular resources for cardiac regeneration.

However, our data failed to demonstrate the superior regenerative effect of proliferative PDGFRa ${ }^{+}$CLCs compared with differentiated aMHC ${ }^{+} \mathrm{CMs}$ after implantation, consistent with a previous report ${ }^{[19]}$. Although PDGFRa ${ }^{+}$CLCs exhibit more proliferative capacity than differentiated $\mathrm{aMHC}^{+} \mathrm{CMs}$, their expansion might be restricted owing to the limited space of the myocardium, especially in a small mouse model. Further experiments using large animal models, such as swine or non-human primates, might be necessary to confirm the regenerative effect of CLCs. In addition, the pathologic microenvironment of damaged heart might affect the proliferation and survival of implanted cells. Indeed, the previous and current data demonstrated that the engraftment of implanted CLCs and CMs was gradually decreased with time. Despite suboptimal engraftment and eventual death of the implanted cells in infarcted myocardium, the regenerative effect of implanted cells might result from differential paracrine effects ${ }^{[2]}$. Recent data demonstrated the significant upregulation of promigratory, proangiogenic, and antiapoptotic gene expression in the infarcted myocardium of groups treated with CMs compared with groups treated with PSCs and the controls ${ }^{[24}$. Our data also revealed enhanced angiogenesis after implantation of PDGFRa ${ }^{+}$CLCs and aMHC ${ }^{+}$CMs. Therefore, the previous and current data suggested that not only direct integration but also the paracrine effect of implanted CLCs and CMs contributes to cardiac regeneration ${ }^{[24]}$. Further studies are needed to better understand the therapeutic mechanisms following transplantation of CLCs and to enhance engraftment. 
Table 1 Echocardiographic parameters of Control, MI, MI+PDGFRa ${ }^{+}$CLCs, and Ml+aMHC+ CMs groups $^{2}$

\begin{tabular}{|c|c|c|c|c|c|c|c|c|c|c|c|}
\hline Group & $\begin{array}{l}\text { LVIDd } \\
(\mathrm{mm})\end{array}$ & $\begin{array}{l}\text { LVIDs } \\
(\mathrm{mm})\end{array}$ & $\begin{array}{l}\text { IVSd } \\
(\mathrm{mm})\end{array}$ & $\begin{array}{l}\text { IVSs } \\
(\mathrm{mm})\end{array}$ & $\begin{array}{l}\text { LVPWd } \\
(\mathrm{mm})\end{array}$ & $\begin{array}{l}\text { LVPWs } \\
\text { (mm) }\end{array}$ & $\begin{array}{l}\text { LVEDV } \\
(\mathrm{mL})\end{array}$ & $\begin{array}{l}\text { LVESV } \\
(\mathrm{mL})\end{array}$ & $\begin{array}{l}\text { LVSV } \\
(\mathrm{mL})\end{array}$ & $\begin{array}{l}\text { LVEF } \\
(\%)\end{array}$ & $\begin{array}{l}\text { FS } \\
(\%)\end{array}$ \\
\hline $\begin{array}{l}\text { Control } \\
(n=7)\end{array}$ & $4.46 \pm 0.23$ & $3.14 \pm 0.14$ & $0.76 \pm 0.07$ & $1.08 \pm 0.05$ & $0.76 \pm 0.10$ & $1.11 \pm 0.07$ & $0.22 \pm 0.04$ & $0.08 \pm 0.01$ & $0.14 \pm 0.03$ & $62.7 \pm 2.52$ & $29.2 \pm 1.72$ \\
\hline $\begin{array}{l}\text { MI } \\
(n=7)\end{array}$ & $5.57 \pm 0.60$ & $5.09 \pm 0.54$ & $0.67 \pm 0.04$ & $0.71 \pm 0.07$ & $0.74 \pm 0.09$ & $1.03 \pm 0.17$ & $0.42 \pm 0.14$ & $0.32 \pm 0.10$ & $0.10 \pm 0.03$ & $22.5 \pm 2.91$ & $8.61 \pm 1.12$ \\
\hline $\begin{array}{l}\text { MI+PDGFRa }{ }^{+} \\
\text {CLCs } \\
(n=7)\end{array}$ & $4.96 \pm 0.38$ & $3.92^{\mathrm{b}} \pm 0.54$ & $0.68 \pm 0.10$ & $0.87 \pm 0.27$ & $0.68 \pm 0.06$ & $0.99 \pm 0.13$ & $0.21^{\mathrm{b}} \pm 0.14$ & $0.12^{\mathrm{b}} \pm 0.08$ & $0.09 \pm 0.06$ & $42.4^{\mathrm{b}} \pm 4.38$ & $18.1^{b} \pm 2.54$ \\
\hline $\begin{array}{l}\mathrm{MI}+\alpha \mathrm{MHC}^{+} \mathrm{CMs} \\
(n=7)\end{array}$ & $5.15 \pm 0.56$ & $4.38 \pm 0.60$ & $0.65 \pm 0.04$ & $0.69 \pm 0.04$ & $0.74 \pm 0.07$ & $1.08 \pm 0.12$ & $0.28^{a} \pm 0.14$ & $0.18^{\mathrm{b}} \pm 0.10$ & $0.10 \pm 0.05$ & $38.1^{b} \pm 6.86$ & $15.8^{\mathrm{b}} \pm 4.79$ \\
\hline
\end{tabular}

${ }^{\mathrm{a}} P<0.05$ vs MI.

${ }^{\mathrm{b}} \mathrm{P}<0.01$ vs MI.

The parameters present as mean \pm SD. LVIDd: Left ventricular internal diameter diastole; LVIDs: Left ventricular internal dimension

systole; IVSd: Interventricular septal diastole; IVSs: Interventricular septal systole; LVPWd: Left ventricular posterior wall diameter diastole; LVPWs: Left ventricular posterior wall diameter systole; LVEDV: Left ventricular end diastolic volume; LVESV: Left ventricular end systolic volume; LVSV: Left ventricular stroke volume; LVEF: Left ventricular ejection fraction; FS: Fractional shortening; CLCs: Cardiac lineage-committed cells; CMs: Cardiomyocytes; MI: Myocardial infarction.

Proper electromechanical integration of PSC-derived CMs into host myocardium is crucial for preventing fatal arrhythmia after transplantation ${ }^{[1]}$. In a recent study, Chong et al ${ }^{[25]}$ reported remuscularization of infarcted myocardium after injection of human ESC-derived CMs into non-human primate models of MI ${ }^{[26]}$. These grafts formed electromechanical junctions with the host myocardium and beat in synchrony, but ventricular arrhythmias were noted after transplantation ${ }^{[25]}$. Another recent study showed that monkey iPSC-derived CMs improved cardiac contractile function after transplantation into infarcted monkey hearts; nonetheless, the incidence of ventricular tachycardia was transiently but significantly increased ${ }^{[27}$. In our study, we could not evaluate the occurrence of ventricular arrhythmia because of the technical difficulties associated with the mouse model. Therefore, further studies using large animal models might be necessary to confirm the arrhythmogenic effect of proliferating CLCs compared with differentiated CMs after transplantation into infarcted heart.

In conclusion, PDGFRa ${ }^{+}$CLCs served as the potential donor population for cardiac regeneration, and our findings provide conceptual and technical advances in stem cell therapy for cardiac regeneration. 
A
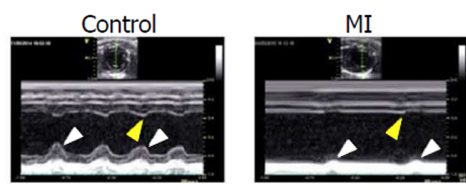

$\mathrm{MI}+\mathrm{PDGFR} \alpha{ }^{+} \mathrm{CLC}$

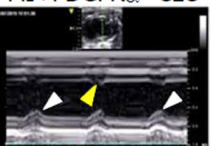

$\mathrm{MI}+\alpha \mathrm{MHC}^{+} \mathrm{CM}$

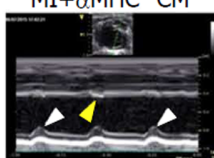

D

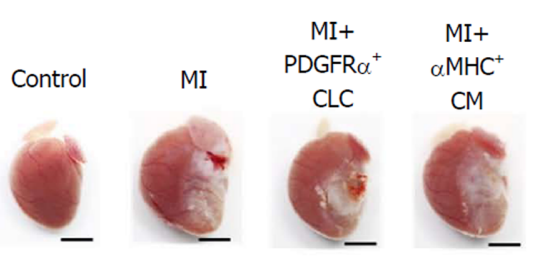

B

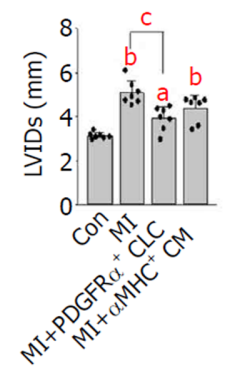

C
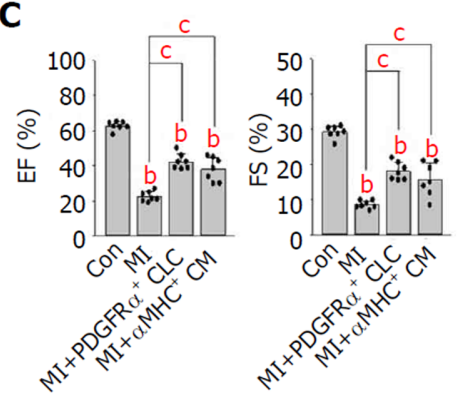

E

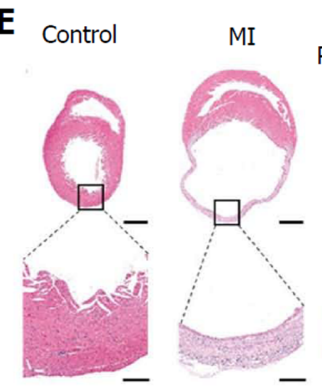

$\mathrm{MI}+$

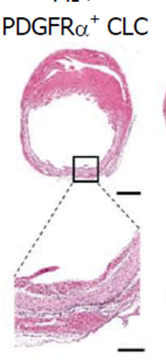

$\mathrm{MI}+$

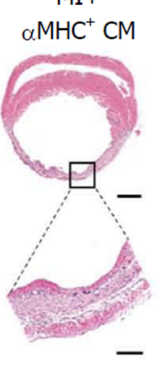

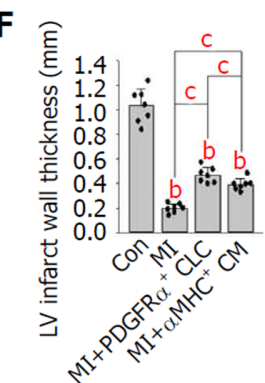

Figure 2 Implantations of platelet-derived growth factor receptor- $\alpha^{+}$cardiac lineage-committed cells and aMHC ${ }^{+}$cardiomyocytes equally improves contractile function and structure in the infarcted heart. A: Representative M-mode transthoracic echocardiography views of control, myocardial infarction (MI), $\mathrm{Ml}+$ platelet-derived growth factor receptor-a (PDGFRa) ${ }^{+}$cardiac lineage-committed cells (CLCs), and Ml+aMHC ${ }^{+}$cardiomyocytes (CMs). Improved anterior (white

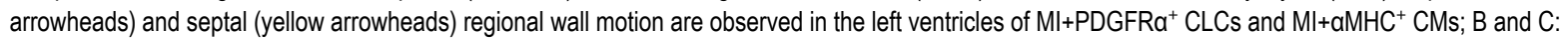

Quantifications of left ventricular internal dimension in systole $(\mathrm{mm})$, ejection fraction (\%) and fractional shortening (\%). Each group, $n=7 .{ }^{\mathrm{a}} P<0.05$ and ${ }^{\mathrm{b}} P<0.01$ vs Con; ${ }^{c} P<0.01$ vs Ml; D: Gross images of hearts in control, MI, Ml+PDGFRa ${ }^{+} \mathrm{CLCs}$, and Ml+aMHC ${ }^{+} \mathrm{CMs}$. Scale bars, $2.5 \mathrm{~mm}$; $\mathrm{E}$ : $\mathrm{H}$ and $\mathrm{E}$ staining of mid-sectioned hearts of control, MI, MI+PDGFRa ${ }^{+} \mathrm{CLCs}$, and Ml+aMHC ${ }^{+} \mathrm{CMs}$. Scale bars, $1 \mathrm{~mm}$ and $50 \mu \mathrm{m}$ in the upper and lower panels, respectively; F: Quantifications of the thickness $(\mathrm{mm})$ of left ventricle in the infarcted region. Each group, $n=7 .{ }^{\mathrm{b}} P<0.01 \mathrm{vs}$ Con; ${ }^{\mathrm{c}} P<0.01 \mathrm{vs} \mathrm{Ml}$ or MI+PDGFRa ${ }^{+} \mathrm{CLCs}$. CLCs: Cardiac lineage-committed cells; CMs: Cardiomyocytes; Ml: Myocardial infarction.

A

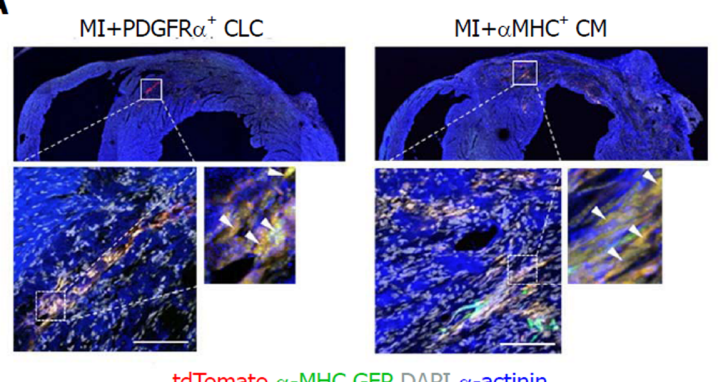

B

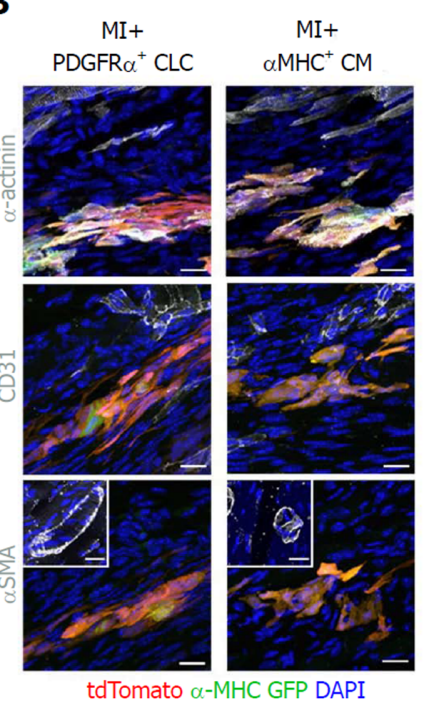

C

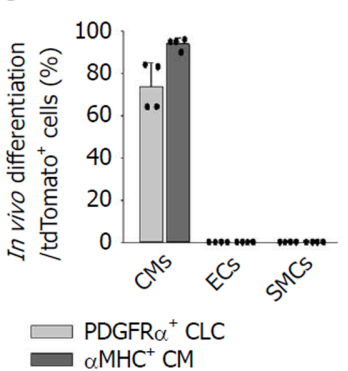

Figure 3 Integration and differentiation of implanted platelet-derived growth factor receptor- $\alpha^{+}$cardiac lineage-committed cells in the infarcted heart. A: tdTomato-tagged platelet-derived growth factor receptor-a (PDGFRa) $)^{+}$cardiac lineage-committed cells (CLCs) or aMHC ${ }^{+}$cardiomyocytes (CMs) were implanted into the infracted myocardium and integration was confirmed by immunostaining. tdTomato $/ a-M H C-\mathrm{GFP}^{+}$cells (white arrowheads) are implanted PDGFRa ${ }^{+} \mathrm{CLCs}_{\mathrm{C}}$ and $\mathrm{aMHC}^{+} \mathrm{CMs}$. Scale bars, $100 \mu \mathrm{m} ; \mathrm{B}$ : Representative confocal images showing differentiation of tdTomato ${ }^{+} \mathrm{PDGFRa}^{+} \mathrm{CLCs}_{\text {and }} \mathrm{aMHC}^{+} \mathrm{CMs}$ into cardiomyocytes 15 $\mathrm{d}$ after the implantation. aSMA-expressing cells were negative for tdTomato or a-MHC-GFP signal as shown in the inlet. Scale bars, $25 \mu \mathrm{m}$; $\mathrm{C}$ : Percentages of $\alpha$ actinin $^{+} \mathrm{CMs}, \mathrm{CD} 31$ endothelial cells and aSMA ${ }^{+}$smooth muscle cells of the implanted PDGFRa ${ }^{+} \mathrm{CLCs}$ and aMHC ${ }^{+} \mathrm{CMs}$. Each group, $n=4$. Scale bars, $20 \mu \mathrm{m}$. CLCs: Cardiac lineage-committed cells; CMs: Cardiomyocytes; MI: Myocardial infarction; ECs: Endothelial cells; SMCs: Smooth muscle cells. 
A

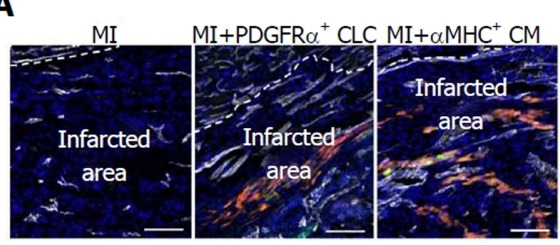

a-MHC GFP tdTomato CD31 DAPI

$\mathbf{E}$

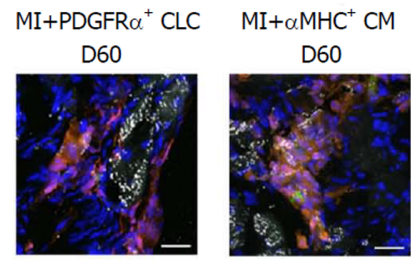

$\alpha$-MHC GFP tdTomato $\alpha$-actinin DAPI
B

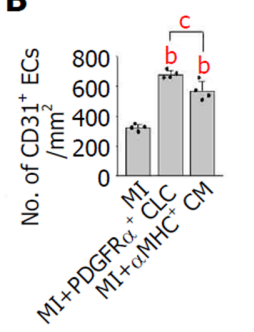

C
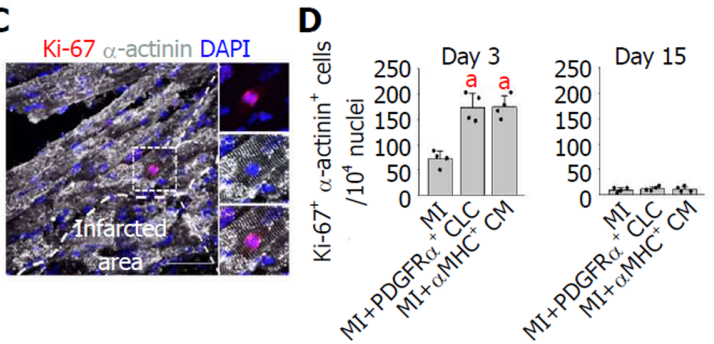

$\mathbf{F}$

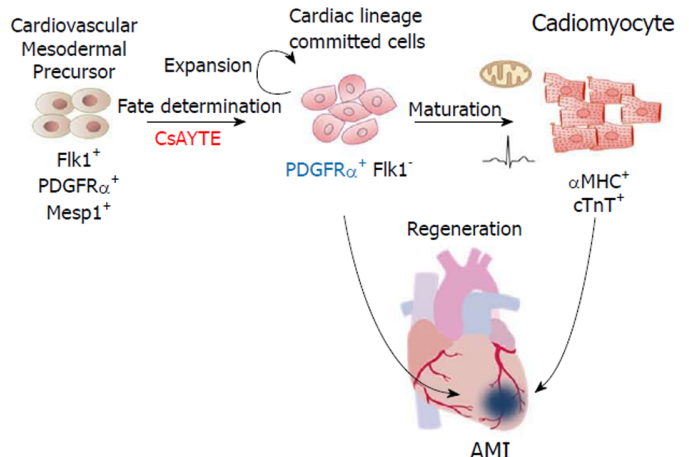

Figure 4 Proliferation and survival of implanted platelet-derived growth factor receptor- $\alpha^{+}$cardiac lineage-committed cells in the infarcted heart. A: Representative confocal image of $\mathrm{Ki}-67^{+}$host cardiomyocytes in the peri-infarcted region $3 \mathrm{~d}$ after cell injection. Dotted-lined rectangular region is magnified in right. Scale bar, $50 \mu \mathrm{m}$; B: Quantifications of Ki- $67^{+} \alpha$-actinin ${ }^{+}$cardiomyocytes per $10^{4}$ nuclei in the peri-infarcted region 3 and $15 \mathrm{~d}$ after the implantation. Each group, $n=4$. ${ }^{a} P<0.05$ vs myocardial infarction (Ml); C: Representative confocal images of revascularization within the infarcted areas $15 \mathrm{~d}$ after the implantation. Scale bars, 100 $\mu \mathrm{m}$; D: Quantifications of capillary density (No. of CD31+ ECs $/ \mathrm{mm}^{2}$ ) within the infarcted areas. Each group, $n=4$. ${ }^{\mathrm{b}} P<0.01 \mathrm{vs} \mathrm{Ml}$; ${ }^{\mathrm{c}} P<0.01 \mathrm{vs} \mathrm{Ml}+$ platelet-derived growth factor receptor-a (PDGFRa) ${ }^{+}$cardiac lineage-committed cells (CLCs); E: Representative confocal images of tdTomato ${ }^{+}$PDGFRa $^{+} \mathrm{CLCs}_{\text {and }} \mathrm{aMHC}^{+} \mathrm{CMs} 60$ $\mathrm{d}$ after the implantation. Three independent experiments showed similar findings. Scale bars, $20 \mu \mathrm{m}$; F: Schematic diagram illustrating the regenerative potential of PDGFRa ${ }^{+}$CLCs in the infarcted heart. CLCs: Cardiac lineage-committed cells; CMs: Cardiomyocytes; Ml: Myocardial infarction.

\section{ARTICLE HIGHLIGHTS}

\section{Research background}

Pluripotent stem cell (PSC)-derived cardiomyocytes (CMs) have become one of the most attractive cellular resources for cell-based therapy to rescue damaged cardiac tissue.

\section{Research motivation}

The proliferative capacity of PSC-derived CMs is decreased after beating and terminal differentiation. Furthermore, there is no definite surface marker of differentiated PSC-derived CMs to facilitate purification.

\section{Research objectives}

We investigated the regenerative potential of mouse embryonic stem cell-derived PDGFRa ${ }^{+}$ cardiac lineage-committed cells (CLCs) in a murine myocardial infarction (MI) model and compared their efficacy with differentiated CMs.

\section{Research methods}

We implanted platelet-derived growth factor receptor-a (PDGFRa) ${ }^{+}$CLCs and differentiated $\mathrm{aMHC}^{+} \mathrm{CMs}$ into a MI murine model and performed functional analysis using transthoracic echocardiography (TTE) and histologic analysis.

\section{Research results}

Compared with the untreated MI hearts, the anterior and septal regional wall motion and systolic functional parameters were notably and similarly improved in the MI hearts implanted with PDGFRa ${ }^{+}$CLCs and $\mathrm{aMHC}^{+} \mathrm{CMs}$ based on TTE. In histologic analysis, the untreated MI hearts contained a thinner ventricular wall than did the controls, while the ventricular walls of MI hearts implanted with PDGFRa ${ }^{+} \mathrm{CLCs}$ and $\mathrm{aMHC}^{+} \mathrm{CMs}$ were similarly thicker compared with that of the untreated MI hearts. Furthermore, implanted PDGFRa ${ }^{+}$CLCs aligned and integrated with host $\mathrm{CMs}$ and were mostly differentiated into a-actinin ${ }^{+} \mathrm{CMs}$, and they did not convert into $\mathrm{CD}^{+} 1^{+}$endothelial cells or aSMA ${ }^{+}$mural cells.

\section{Research conclusions}

PDGFRa ${ }^{+}$CLCs from mouse ESCs exhibiting proliferative capacity showed a regenerative effect in infarcted myocardium. Therefore, mouse ESC-derived PDGFRa ${ }^{+}$CLCs may represent a potential cellular resource for cardiac regeneration. 
Research perspectives

PDGFRa ${ }^{+}$CLCs served as the potential donor population for cardiac regeneration, and our findings provide conceptual and technical advances in stem cell therapy for cardiac regeneration.

\section{ACKNOWLEDGEMENTS}

We thank Professor Gou Young Koh for technical advice and valuable discussions. We also thank Su Jin Seo and Sam Mi Yoo for their technical assistance.

\section{REFERENCES}

1 Segers VF, Lee RT. Stem-cell therapy for cardiac disease. Nature 2008; 451: 937-942 [PMID: 18288183 DOI: 10.1038/nature06800]

2 Passier R, van Laake LW, Mummery CL. Stem-cell-based therapy and lessons from the heart. Nature 2008; 453: 322-329 [PMID: 18480813 DOI: 10.1038/nature07040]

3 Chow A, Stuckey DJ, Kidher E, Rocco M, Jabbour RJ, Mansfield CA, Darzi A, Harding SE, Stevens MM, Athanasiou T. Human Induced Pluripotent Stem Cell-Derived Cardiomyocyte Encapsulating Bioactive Hydrogels Improve Rat Heart Function Post Myocardial Infarction. Stem Cell Reports 2017; 9: 1415-1422 [PMID: 28988988 DOI: 10.1016/j.stemcr.2017.09.003]

4 Gao L, Gregorich ZR, Zhu W, Mattapally S, Oduk Y, Lou X, Kannappan R, Borovjagin AV, Walcott GP, Pollard AE, Fast VG, Hu X, Lloyd SG, Ge Y, Zhang J. Large Cardiac Muscle Patches Engineered From Human Induced-Pluripotent Stem Cell-Derived Cardiac Cells Improve Recovery From Myocardial Infarction in Swine. Circulation 2018; 137: 1712-1730 [PMID: 29233823 DOI: 10.1161/CIRCULATIONAHA.117.030785]

5 Robertson C, Tran DD, George SC. Concise review: maturation phases of human pluripotent stem cellderived cardiomyocytes. Stem Cells 2013; 31: 829-837 [PMID: 23355363 DOI: 10.1002/stem.1331]

6 Skelton RJP, Kamp TJ, Elliott DA, Ardehali R. Biomarkers of Human Pluripotent Stem Cell-Derived Cardiac Lineages. Trends Mol Med 2017; 23: 651-668 [PMID: 28576602 DOI: 10.1016/j.molmed.2017.05.001]

7 Takeda M, Kanki Y, Masumoto H, Funakoshi S, Hatani T, Fukushima H, Izumi-Taguchi A, Matsui Y, Shimamura T, Yoshida Y, Yamashita JK. Identification of Cardiomyocyte-Fated Progenitors from HumanInduced Pluripotent Stem Cells Marked with CD82. Cell Rep 2018; 22: 546-556 [PMID: 29320747 DOI: 10.1016/j.celrep.2017.12.057]

8 Ishida H, Saba R, Kokkinopoulos I, Hashimoto M, Yamaguchi O, Nowotschin S, Shiraishi M, Ruchaya P, Miller D, Harmer S, Poliandri A, Kogaki S, Sakata Y, Dunkel L, Tinker A, Hadjantonakis AK, Sawa Y, Sasaki H, Ozono K, Suzuki K, Yashiro K. GFRA2 Identifies Cardiac Progenitors and Mediates Cardiomyocyte Differentiation in a RET-Independent Signaling Pathway. Cell Rep 2016; 16: 1026-1038 [PMID: 27396331 DOI: 10.1016/j.celrep.2016.06.050]

9 Yoon C, Song H, Yin T, Bausch-Fluck D, Frei AP, Kattman S, Dubois N, Witty AD, Hewel JA, Guo H, Emili A, Wollscheid B, Keller G, Zandstra PW. FZD4 Marks Lateral Plate Mesoderm and Signals with NORRIN to Increase Cardiomyocyte Induction from Pluripotent Stem Cell-Derived Cardiac Progenitors. Stem Cell Reports 2018; 10: 87-100 [PMID: 29249665 DOI: 10.1016/j.stemcr.2017.11.008]

10 Nelson DO, Lalit PA, Biermann M, Markandeya YS, Capes DL, Addesso L, Patel G, Han T, John MC, Powers PA, Downs KM, Kamp TJ, Lyons GE. Irx4 Marks a Multipotent, Ventricular-Specific Progenitor Cell. Stem Cells 2016; 34: 2875-2888 [PMID: 27570947 DOI: 10.1002/stem.2486]

11 Hong SP, Song S, Cho SW, Lee S, Koh BI, Bae H, Kim KH, Park JS, Do HS, Im I, Heo HJ, Ko TH, Park JH, Youm JB, Kim SJ, Kim I, Han J, Han YM, Koh GY. Generation of PDGFR $\alpha+$ Cardioblasts from Pluripotent Stem Cells. Sci Rep 2017; 7: 41840 [PMID: 28165490 DOI: 10.1038/srep41840]

12 Hirai H, Ogawa M, Suzuki N, Yamamoto M, Breier G, Mazda O, Imanishi J, Nishikawa S. Hemogenic and nonhemogenic endothelium can be distinguished by the activity of fetal liver kinase (Flk)-1 promoter/enhancer during mouse embryogenesis. Blood 2003; 101: 886-893 [PMID: 12393724 DOI: 10.1182/blood-2002-02-0655]

13 Yamashita JK, Takano M, Hiraoka-Kanie M, Shimazu C, Peishi Y, Yanagi K, Nakano A, Inoue E, Kita F, Nishikawa S. Prospective identification of cardiac progenitors by a novel single cell-based cardiomyocyte induction. FASEB J 2005; 19: 1534-1536 [PMID: 16033809 DOI: 10.1096/fj.04-3540fje]

14 Kodama H, Nose M, Niida S, Nishikawa S, Nishikawa S. Involvement of the c-kit receptor in the adhesion of hematopoietic stem cells to stromal cells. Exp Hematol 1994; 22: 979-984 [PMID: 7522185 DOI: 10.1111/j.1365-2362.1994.tb01116.x]

15 Rompani SB, Cepko CL. Retinal progenitor cells can produce restricted subsets of horizontal cells. Proc Natl Acad Sci USA 2008; 105: 192-197 [PMID: 18162542 DOI: 10.1073/pnas.0709979104]

16 Dull T, Zufferey R, Kelly M, Mandel RJ, Nguyen M, Trono D, Naldini L. A third-generation lentivirus vector with a conditional packaging system. J Virol 1998; 72: 8463-8471 [PMID: 9765382 DOI: 10.1016/S0166-0934(98)00117-7]

17 Cho SW, Park JS, Heo HJ, Park SW, Song S, Kim I, Han YM, Yamashita JK, Youm JB, Han J, Koh GY Dual modulation of the mitochondrial permeability transition pore and redox signaling synergistically promotes cardiomyocyte differentiation from pluripotent stem cells. J Am Heart Assoc 2014; 3: e000693 [PMID: 24627421 DOI: 10.1161/JAHA.113.000693]

18 Liu Y, Chen L, Diaz AD, Benham A, Xu X, Wijaya CS, Fa'ak F, Luo W, Soibam B, Azares A, Yu W, Lyu Q, Stewart MD, Gunaratne P, Cooney A, McConnell BK, Schwartz RJ. Mesp1 Marked Cardiac Progenitor Cells Repair Infarcted Mouse Hearts. Sci Rep 2016; 6: 31457 [PMID: 27538477 DOI: 10.1038/srep31457]

19 Fernandes S, Chong JJH, Paige SL, Iwata M, Torok-Storb B, Keller G, Reinecke H, Murry CE. Comparison of Human Embryonic Stem Cell-Derived Cardiomyocytes, Cardiovascular Progenitors, and Bone Marrow Mononuclear Cells for Cardiac Repair. Stem Cell Reports 2015; 5: 753-762 [PMID: 26607951 DOI: 10.1016/j.stemcr.2015.09.011]

20 Ghazizadeh Z, Fattahi F, Mirzaei M, Bayersaikhan D, Lee J, Chae S, Hwang D, Byun K, Tabar MS, Taleahmad S, Mirshahvaladi S, Shabani P, Fonoudi H, Haynes PA, Baharvand H, Aghdami N, Evans T, 
Lee B, Salekdeh GH. Prospective Isolation of ISL1+ Cardiac Progenitors from Human ESCs for Myocardial Infarction Therapy. Stem Cell Reports 2018; 10: 848-859 [PMID: 29503094 DOI: 10.1016/j.stemcr.2018.01.037]

21 Bartulos O, Zhuang ZW, Huang Y, Mikush N, Suh C, Bregasi A, Wang L, Chang W, Krause DS, Young LH, Pober JS, Qyang Y. ISL1 cardiovascular progenitor cells for cardiac repair after myocardial infarction. JCI Insight 2016; 1: pii: e80920 [PMID: 27525311 DOI: 10.1172/jci.insight.80920]

22 Zhang Y, Cao N, Huang Y, Spencer CI, Fu JD, Yu C, Liu K, Nie B, Xu T, Li K, Xu S, Bruneau BG, Srivastava D, Ding S. Expandable Cardiovascular Progenitor Cells Reprogrammed from Fibroblasts. Cell Stem Cell 2016; 18: 368-381 [PMID: 26942852 DOI: 10.1016/j.stem.2016.02.001]

23 Lalit PA, Salick MR, Nelson DO, Squirrell JM, Shafer CM, Patel NG, Saeed I, Schmuck EG, Markandeya YS, Wong R, Lea MR, Eliceiri KW, Hacker TA, Crone WC, Kyba M, Garry DJ, Stewart R, Thomson JA, Downs KM, Lyons GE, Kamp TJ. Lineage Reprogramming of Fibroblasts into Proliferative Induced Cardiac Progenitor Cells by Defined Factors. Cell Stem Cell 2016; 18: 354-367 [PMID: 26877223 DOI: 10.1016/j.stem.2015.12.001]

24 Tachibana A, Santoso MR, Mahmoudi M, Shukla P, Wang L, Bennett M, Goldstone AB, Wang M, Fukushi M, Ebert AD, Woo YJ, Rulifson E, Yang PC. Paracrine Effects of the Pluripotent Stem CellDerived Cardiac Myocytes Salvage the Injured Myocardium. Circ Res 2017; 121: e22-e36 [PMID: 28743804 DOI: 10.1161/CIRCRESAHA.117.310803]

25 Chong JJ, Yang X, Don CW, Minami E, Liu YW, Weyers JJ, Mahoney WM, Van Biber B, Cook SM, Palpant NJ, Gantz JA, Fugate JA, Muskheli V, Gough GM, Vogel KW, Astley CA, Hotchkiss CE, Baldessari A, Pabon L, Reinecke H, Gill EA, Nelson V, Kiem HP, Laflamme MA, Murry CE. Human embryonic-stem-cell-derived cardiomyocytes regenerate non-human primate hearts. Nature 2014; 510: 273-277 [PMID: 24776797 DOI: 10.1038/nature13233]

26 Liu YW, Chen B, Yang X, Fugate JA, Kalucki FA, Futakuchi-Tsuchida A, Couture L, Vogel KW, Astley CA, Baldessari A, Ogle J, Don CW, Steinberg ZL, Seslar SP, Tuck SA, Tsuchida H, Naumova AV, Dupras SK, Lyu MS, Lee J, Hailey DW, Reinecke H, Pabon L, Fryer BH, MacLellan WR, Thies RS, Murry CE. Human embryonic stem cell-derived cardiomyocytes restore function in infarcted hearts of non-human primates. Nat Biotechnol 2018; 36: 597-605 [PMID: 29969440 DOI: 10.1038/nbt.4162]

27 Shiba Y, Gomibuchi T, Seto T, Wada Y, Ichimura H, Tanaka Y, Ogasawara T, Okada K, Shiba N, Sakamoto K, Ido D, Shiina T, Ohkura M, Nakai J, Uno N, Kazuki Y, Oshimura M, Minami I, Ikeda U. Allogeneic transplantation of iPS cell-derived cardiomyocytes regenerates primate hearts. Nature 2016; 538: 388-391 [PMID: 27723741 DOI: 10.1038/nature19815]

P- Reviewer: Labusca L, Pixley JS, Wakao H S- Editor: Ji FF L-Editor: A E- Editor: Tan WW 


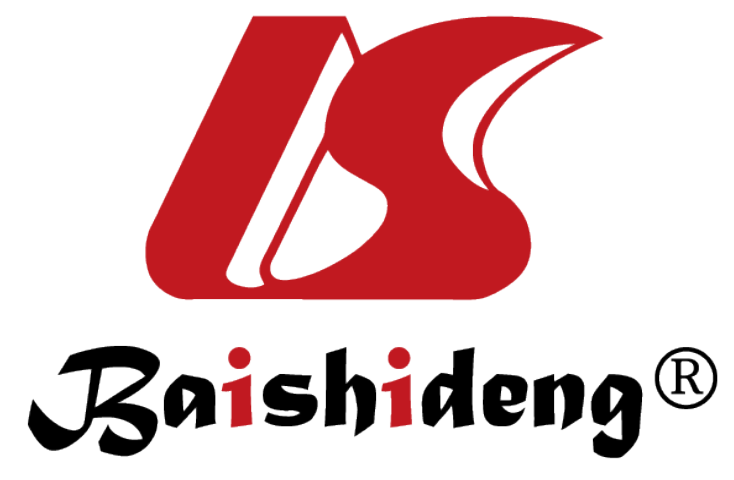

Published By Baishideng Publishing Group Inc 7901 Stoneridge Drive, Suite 501, Pleasanton, CA 94588, USA Telephone: +1-925-2238242

Fax: +1-925-2238243

E-mail: bpgoffice@wjgnet.com

Help Desk: https://www.f6publishing.com/helpdesk

https://www.wjgnet.com

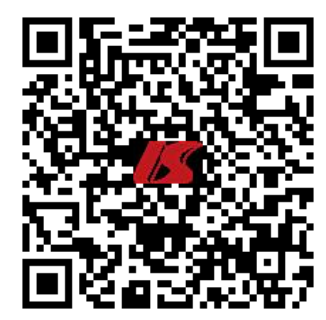

